\title{
Mulher e Água: definições e novas representações
}

DOSSIER ÁGUA E MULHER

\section{Nathalie Cristine Gallo}

Mestranda no Programa Ensino e História de Ciências da Terra. Universidade Estadual de Campinas, Instituto de Geociências. Campinas [São Paulo] Brasil. <nathaliecristinegallo21@gmail.com>

\section{Anna Carolina Lourenço Navarro}

Mestranda do Programa em Política Científica e Tecnológica. Universidade Estadual de Campinas, Instituto de Geociências. Campinas [São Paulo] Brasil. <annacarolinaln@gmail.com>

\section{Resumo}

Por meio de uma pesquisa bibliográfica, o objetivo deste trabalho é estabelecer a relação mulher e água e atualizar esta definição. Nesta questão, ambas - mulher e água tem o poder de tornarem-se objeto e sujeito da história não somente devido às conquistas do público feminino ao longo dos tempos por seus direitos. A temática aqui apresentada tem o compromisso de ir além dos direitos alcançados e da associação da mulher em ter como principais funções os afazeres domésticos, o parto e os direitos femininos, que são importantes. Mas graças à reflexão destes é fundamental abrir um leque de possibilidades que se tem para associar, comparar, relacionar e correlacionar água e mulher do ponto de vista histórico, artístico, social e cultural. Tais reflexões deste estudo colaboram para a atualização da visão que se deve ter do papel da mulher nos diversos momentos relacionados à água, em variados cenários e contextos em que ambas estão inseridas conjuntamente.

\section{Palavras-chave}

Mulher. Água. Objeto. Representação. Sujeito da história.

\section{Woman and Water: definitions and new representations}

\begin{abstract}
Through a bibliographical research, the objective of this work is to establish the relationship between woman and water and to update this definition. In this matter, both woman and water have the power to become the object and subject of history not only because of the female achievements over time. The theme presented here is committed to go beyond the rights achieved and the association of the women to the domestic duties and childbirth. It is fundamental to open up a range of possibilities to associate, compare, relate and correlate water and women from a historical, artistic, social and cultural point of view. The reflections from this article collaborate to update the vision and the relationship related to the woman and water in different scenarios and contexts.
\end{abstract}

\section{Keywords}

Woman. Water. Object. Representation. Subject of history. 


\section{Introdução}

A relação mulher e água é muito profunda e vai além ao contato de ambas nos trabalhos domésticos, ao que diz respeito à lavagem das mãos, da louça, limpeza da casa, cozinhar e lavar roupas. Embora haja muitas e diferentes definições tanto do vocábulo mulher como da palavra água, a organização entre mulher e água não é atual. Mulher e água são sinônimos de vida.

No contexto de muitas comunidades em diferentes regiões, cabe à mulher a responsabilidade de buscar água, e para isso, acaba exercendo uma rotina estafante e perigosa, devido a longas distâncias que necessita percorrer e aos transtornos que pode encontrar durante o trajeto.

Por meio de uma pesquisa bibliográfica, o objetivo deste trabalho é atualizar a definição da relação entre mulher e água, propondo reflexões acerca dessa temática, bem como apontar a importância da participação maior do papel feminino na tomada de decisões sobre a gestão da água.

Várias associações podem ser feitas entre os dois objetos deste trabalho - mulher e água. 0 público feminino possui relação com a água desde o momento da concepção de uma criança, do período de gestação ao parto, a amamentação, além dos tratamentos e cuidados femininos na lavagem do corpo, dos cabelos, utilização de cremes e demais momentos dedicados à preocupação com sua beleza também merecem destaque. Além disso, a relação entre mulher e água se reflete na literatura, arte, cultura e no contexto histórico da conquista da mulher por seus direitos. Neste enredo, também é possível chamar a atenção para aspectos sociais, como a importância maior e não mais seletiva de sua participação na sociedade ao que rege a gestão de recursos hídricos, comitês de bacias hidrográficas e demais grupos, que, infelizmente, em sua maioria ainda são ocupados predominantemente ou totalmente pelo público masculino, o qual acaba sendo protagonista nas tomadas de decisões. Portanto, é preciso modificar esse cenário, ainda mais no momento atual, que é diferente do período patriarcal, do tradicionalismo em que as obrigações da mulher circulavam somente em torno das tarefas domésticas, gerar filhos e dedicar-se ao marido.

A visão diferenciada através do assunto mulher e água contribui muito para a defesa da importância de buscar, em sua prática, a igualdade de gênero, e pretende estimular a reflexão do quanto é necessária a mudança de pensamentos patriarcais/tradicionais, popularmente indicados como "machistas", além da conscientização de aprimorar as conquistas femininas no decorrer dos tempos, ao que diz respeito à incorporação, reconhecimento e permanência de seus direitos ao que se refere à relação mulher e água.

\section{Mulher e água: representação tradicional dessa relação e atualização do contexto}

Por uma determinação histórica, as mulheres sempre tiveram sua identificação social associadas às obrigações e tarefas domiciliares. Pontes (2013) ao citar Fischer (2006), expõe que com a Revolução Industrial essa condição começou a levemente, se alterar, uma vez que a industrialização criou novas oportunidades de trabalho para homens e mulheres - ainda que, em menor escala para elas. Ambos os autores dialogam com Guiraldelli (2012), ao afirmarem que:

São recorrentes as literaturas que consideram a incorporação do trabalho feminino de forma mais expressiva no findar do século XVIII e início do século XIX, fase que marca a consolidação capitalista, quando as mulheres foram absorvidas pelas indústrias para exercerem inúmeras atividades (Guiraldelli, 2012, p. 709).

Ao longo dos séculos, as mulheres foram se incorporando às fábricas, às indústrias, além de outros ramos e atividades de trabalho. No entanto, durante todo esse processo, as condições de trabalho das mulheres sempre foram inferiores às condições e oportunidades oferecidas aos homens. Apesar de observar-se um crescimento dos movimentos emancipatórios feministas ao longo dos últimos anos, a igualdade social está longe de ser alcançada (Pontes, 2013).

Costa e Androsio ([s.d], p. 10) escrevem que os movimentos feministas iniciados nas décadas de 60 e 70 formaram "a vanguarda revolucionária da luta das mulheres ao problematizarem a (des)igualdade entre homens e mulheres e questionar os diversos aspectos da vida social, como 
a família, sexualidade, tarefas domésticas, inserção no mercado de trabalho e educação dos filhos". Sendo assim, de acordo com as autoras, após esse momento, passou a ser discutido o modo de vida da mulher com mais veemência tanto na sociedade, como nos estudos científicos. Rodrigues ([s.d], pp. 5-6) conta que o movimento feminista surgiu nos Estados Unidos, na segunda metade dos anos sessenta e expandiu-se pelo Ocidente, propagando a libertação da mulher e sua emancipação. Segundo a autora, emancipar refere-se à busca da igualdade em direitos, políticos, jurídicos e econômicos em relação aos homens, enquanto que libertar-se é realçar as condições de diversidade nas relações de gênero para que a mulher passe a ser vista como um indivíduo autônomo e independente. A autora ainda relata que muitas mulheres participaram da ditadura militar, e entre 1970 e 1980 o movimento feminista defendeu a redemocratização do país, surgindo movimentos como a Rede de Mulher, em defesa dos critérios da mulher e da cidadania feminina; aos poucos, elas foram se organizando em vários movimentos, como de trabalhadoras rurais e urbanas, empresárias, e, em 1977, o movimento feminista passou a seguir tendências como a descriminalização do aborto e a equiparação profissional com os homens. A partir daí, de acordo com Rodrigues ([s.d], p. 7) muitas mulheres conseguiram conquistar postos de trabalho ocupados por homens e até cargos políticos. Sendo assim, dentro do contexto desse trabalho é importante salientar que a desigualdade de gênero também tem uma forte relação com a falta de acesso à água (Neves-Silva \& Heller, 2015; Fiocruz Minas, 2016).

Dentre as diversas literaturas é possível conhecer várias significações que são feitas ao termo "mulher". Segundo o dicionário do Aurélio online (2018) mulher significa: "(1) pessoa adulta do sexo feminino; (2) cônjuge ou pessoa do sexo feminino com quem se mantém uma relação sentimental e/ou sexual; (3) mulher pública: meretriz". Já água, possui 33 significados diferentes, de acordo com o mesmo dicionário, porém, entre eles, para a finalidade deste trabalho são mais importantes as definições: "(1) líquido natural $\left(\mathrm{H}_{2} \mathrm{O}\right)$, transparente, incolor, geralmente insípido e inodoro, indispensável para a sobrevivência da maior parte dos seres vivos; (2) esse líquido como recurso natural que cobre cerca de $70 \%$ da superfície terrestre" e também outras: "(4) chuva; (5) suor; (6) lágrimas; (18) líquido amniótico".

Santos ([s.d], p. 1) apresenta o final do século XIX e as primeiras décadas do século XX, primeiramente explicando que à época as práticas populares de vida tornaram-se objeto de preocupação de médicos, sanitaristas, filantropos e reformadores sociais e de setores da burguesia, e comenta que este período foi marcado por um projeto político que se baseava em transformar o país em uma nação civilizada, culta e "moderna", por estar representada "pela importação dos costumes europeus figurava como passaporte para a ordem e o progresso da jovem república brasileira". Desta forma, a autora expõe que neste contexto o projeto de moralização da sociedade brasileira nas décadas iniciais do século XX incluía a formação de um trabalhador dócil, submisso e economicamente produtivo, e uma redefinição da família:

Para tanto, a redefinição da família constitui peça mestra no projeto de normatização da sociedade. Nesse sentido, era tarefa urgente criar um modelo imaginário de mulher, voltada para a intimidade do lar, e também um cuidado especial com a infância, redirecionada para a escola ou os institutos de assistência social (Santos, p. 2).

Por meio desta afirmação é possível levantar que, muitas vezes, a principal significação dada à mulher é tratá-la como aquela que cuida do lar, da família, dos filhos e do marido, ou associá-la à prática de afazeres domésticos. Conforme aponta Pontes (2013, p. 15) por uma imposição histórica, "as mulheres tiveram a sua identificação social relacionada com referência a casa, à família, às obrigações para com os maridos, filhos e a socialização familiar". Borsa e Feil (2008, p. 5) completam esse raciocínio, ao dizerem que a ideia da maternidade como imposição ou condição imposta à mulher foi duramente criticada pelo movimento feminista. "A partir dos anos sessenta encontramos nos discursos de importantes representantes deste movimento a proposição de que a maternidade seria uma condição da qual toda mulher deveria tentar escapar". De acordo com as autoras, isto porque nessa condição a mulher seria submetida a uma maior opressão por parte do homem.

Essa "imagem" da mulher apenas como principal responsável pelos trabalhos domésticos e maternidade está sendo modificada, principalmente, devido a muitas conquistas já alcançadas no 
decorrer dos anos. 0 público feminino vem atingindo cada vez mais direitos de igualdade em relação aos homens e reconhecimento no Mercado de trabalho:

As mudanças nos papeis de homens e mulheres dentro do âmbito familiar estão relacionadas às alterações econômicas e sociais (morais). Como consequência, passaram a ser constituídas distintas formas de conjugalidade a partir do momento em que o matrimônio deixou de ser o meio social para procriação e deu-se autonomia à sexualidade, ou seja, o casamento deixa de ser necessário como condição para o sexo. $O$ trabalho feminino também influenciou esse panorama de forma marcante, desde que entrou em conflito com o estatuto sexual de dominação masculina (Ferreira, 2002).

Costa e Androsio ([s.d], p. 5); argumentam que antes os papeis eram preestabelecidos dentro da família, mas hoje isso já não está acontecendo com tanta frequência, pois está existindo uma individualidade na qual pai, mãe e filho lutam por seus direitos, igualdades e identidade, sem necessariamente deixar de ser família apesar da redefinição dos papeis.

Para ambos, marido e esposa, o trabalho fora de casa seria uma forma de se tratarem com igualdade, principalmente nos afazeres domésticos, tendo que dividir as tarefas do lar e a educação dos filhos (Costa \& Androsio, [s.d], p. 5).

Apesar das mulheres estarem adquirindo cada vez mais novas "visões" sobre si mesmas, alcançando um pouco mais de reconhecimento sob o ponto de vista tanto do público masculino como feminino, este cenário era bem diferenciado anteriormente:

No imaginário do século XIX e XX, o sexo feminino estava à mercê de seu aparelho reprodutivo, que, segundo se acreditava, tornava seu comportamento emocional errático e imprevisivel. Nesse momento, a imagem construída para a mulher destacava a sua fragilidade física, da qual decorriam sua delicadeza e debilidade moral (Santos, [s.d], p. 2).

Já na atualidade, ainda ocorre, como expõem Costa e Androsio, ([s.d], p. 7) que o estereótipo de gênero por vezes se mistura ao estereótipo das tarefas, de forma que: [...]

[...] sendo algumas consideradas tarefas predominantemente femininas e outras masculinas. Sendo o trabalho doméstico exercido pelo homem visto como uma 'ajuda' à mulher e não como responsabilidade do homem no zelo pela casa.

As autoras comentam ([s.d], p. 6) que "observa-se que, nas últimas décadas, um número crescente de pais que também compartilham com a mulher essa tarefa educativa e a responsabilidade sobre os filhos, buscando adequarem-se à nova realidade familiar" e que ([s.d], p. 2) devido às mudanças que foram ocorrendo aos longos dos anos na vida pessoal e profissional da mulher, hoje em dia ela tem sido mais independente, uma vez que antigamente "a sociedade impulsionava os pais a ensinarem às mulheres, desde pequenas, que elas deveriam casar-se para cuidar dos filhos, da casa e do marido".

Soihet (1998, p. 77) lembra que começou a trabalhar com a história das mulheres na década de 1970 e chama a atenção para a segunda vaga do feminismo, "ocorrido a partir de fins dos anos 1960, do que resultou um fértil intercâmbio, alçando-se as mulheres à condição de objeto e sujeito da história". Tomando esse gancho, é possível complementar essa citação de maneira a ter uma visão atualizada da mulher, relacionando-a, neste trabalho, ao seu contato com a água, de forma a olhar para a mulher não como objeto e sujeito da história somente graças aos direitos alcançados por ela no decorrer dos tempos, ou mediante e posteriormente estas conquistas, mas enxergá-la sob o viés de representá-la como provedora da vida, estabelecendo precisa relação entre ela e a água, também sinônimo de vida. "A água é essencial para a vida, pois, apesar dos seres humanos conseguirem sobreviver por algumas semanas sem comida, é impossível sobreviver sem água por mais que poucos dias" (Azevedo, Pereira, \& Paiva, 2016, p. 6). Leloup (2000, p. 227) complementa este raciocínio ao dizer que "em uma região onde a água é rara, uma nascente, um poço, é símbolo de vida. Falar de água viva é falar de vida superabundante: oásis. É acreditar que o deserto pode tornar-se um jardim". 
Sendo assim, a mulher é aquela que dá à luz, de forma que para gerar vida, a água precisa estar presente em seu corpo, dentro de seu útero. De acordo com a professora Roseli Nomura, do Departamento de Ginecologia e Obstetrícia da Unifesp (SP), em entrevista para a matéria da Revista Crescer, de Malacarne (2017), "o líquido amniótico começa a ser produzido no início da gestação, na fase embrionária, e é composto pela água vinda do corpo da mãe". Sendo assim, o saco amniótico forma-se doze dias depois da concepção, e trata-se de uma camada fina, translúcida, forte e resistente que envolve o bebê e o fluído durante a gestação, e que se rompe apenas no momento do parto. "Essa bolsa, aliás, é a primeira coisa que os pais conseguem ver no ultrassom na quarta ou quinta semana de gravidez, mesmo antes de ser possível identificar o embrião" (Malacarne, 2017). Desta forma, de acordo com o que escreve a autora, outra função que o líquido exerce é proteger o bebê, pois serve como uma almofada aquosa capaz de defendêlo contra impactos, caso a mãe sofra algum acidente, além de preservar o bebê durante o nascimento, amortecendo as contrações uterinas. Além disso, após a $20^{\underline{a}}$ semana há a interação mais direta entre o líquido e o bebê, de forma que este o inspira e expira, engole e o elimina por meio da urina, o que se trata de um processo saudável (Malacarne, 2017).

Fortes (2006, p. 27-28) corrobora para esta explicação ao descrever que "mergulhar na água, ser envolvido por ela, senti-la por todo o corpo assemelha-se a estar contido no ventre da mãe. A água é uma espécie de mãe universal dos seres, dando-lhes alimento e envolvendo-os e possibilitando-lhe a vida".

Ainda, complementando sobre água, é possível fazer outras analogias utilizando os rios, por exemplo. Segundo Fortes Júnior (2006, p. 35) nas concepções da Idade Média e do Renascimento, "os rios eram formados não pelas águas da chuva e pela evaporação, mas seriam veias que viriam do interior da Terra doando vida à superfície". Este é o tipo de justificativa encontrada ao verificar obras de Leonardo da Vinci e de outros artistas:

Para a historiadora alemã Ute Seiderer, tal concepção explica a maneira como os rios são representados na obra de Leonardo Da Vinci e de muitos outros artistas de seu período. Nestas representações, os rios aparecem como se sua origem fosse no fundo distante da paisagem e serpenteiam até chegar ao primeiro plano do quadro. Além de estar ligada ao desenvolvimento da perspectiva, esta forma de representação também assinala o caráter simbólico da presença da água (Fortes Júnior, 2006, p. 35).

Além do mais, o corpo feminino requer cuidados: o uso de cosméticos, os cuidados no banho, com a pele, a adequada lavagem do cabelo, os cremes, o preparo da pele para a maquilagem e a correta remoção da maquiagem são responsáveis por ressaltar ainda mais a feminilidade, e são possíveis graças à água:

Nos escritos de Leonardo encontram-se considerações a respeito das analogias entre o corpo do homem e o corpo da terra. Nestas analogias, pode-se encontrar, por exemplo, desenhos que aproximam o movimento das correntes aquáticas às tranças de cabelos, ou relações entre os rios e as veias do corpo humano. A associação entre o corpo e a água é tema de freqüentes formulações poéticas na história da arte, quer através da simbologia da água como elemento fundamental para a vida, quer seja pela relação entre a água, umidade e sexualidade ou mesmo devido às significações da água como purificação e meio para a higiene física e espiritual (Fortes Júnior, 2006, p. 35).

Tal afirmação acima, apesar de fazer referência ao corpo do 'homem e o corpo da terra', para este trabalho e dentro da temática aqui discutida, tal citação pode ser aplicada ao corpo da mulher e da Terra, somando dentro desse contexto, a água. Portanto, reconstruindo a associação acima descrita, entre o corpo feminino e a água, uma vez que o autor discute que a associação entre o corpo e a água é tema de formulações poéticas dentro da história da arte, quer seja como simbologia da água como elemento fundamental para a vida, é permissível fundamentar mulher e água como sinônimos de vida, graças à relação que ambas possuem em momentos de umidade, sexualidade, feminilidade, purificação, higiene física e espiritual. Por conseguinte, a água está presente na vida da mulher não apenas na relação já discorrida: afazeres domésticos, beleza ou parto. Água e mulher também se completam na literatura, cultura, na religião e até na arte. Com relação a esta última, Fortes chama a atenção para o quadro de 1546, "A fonte da juventude", do artista alemão Lucas Cranach, o Velho. A imagem pode ser apreciada na Figura 1. 


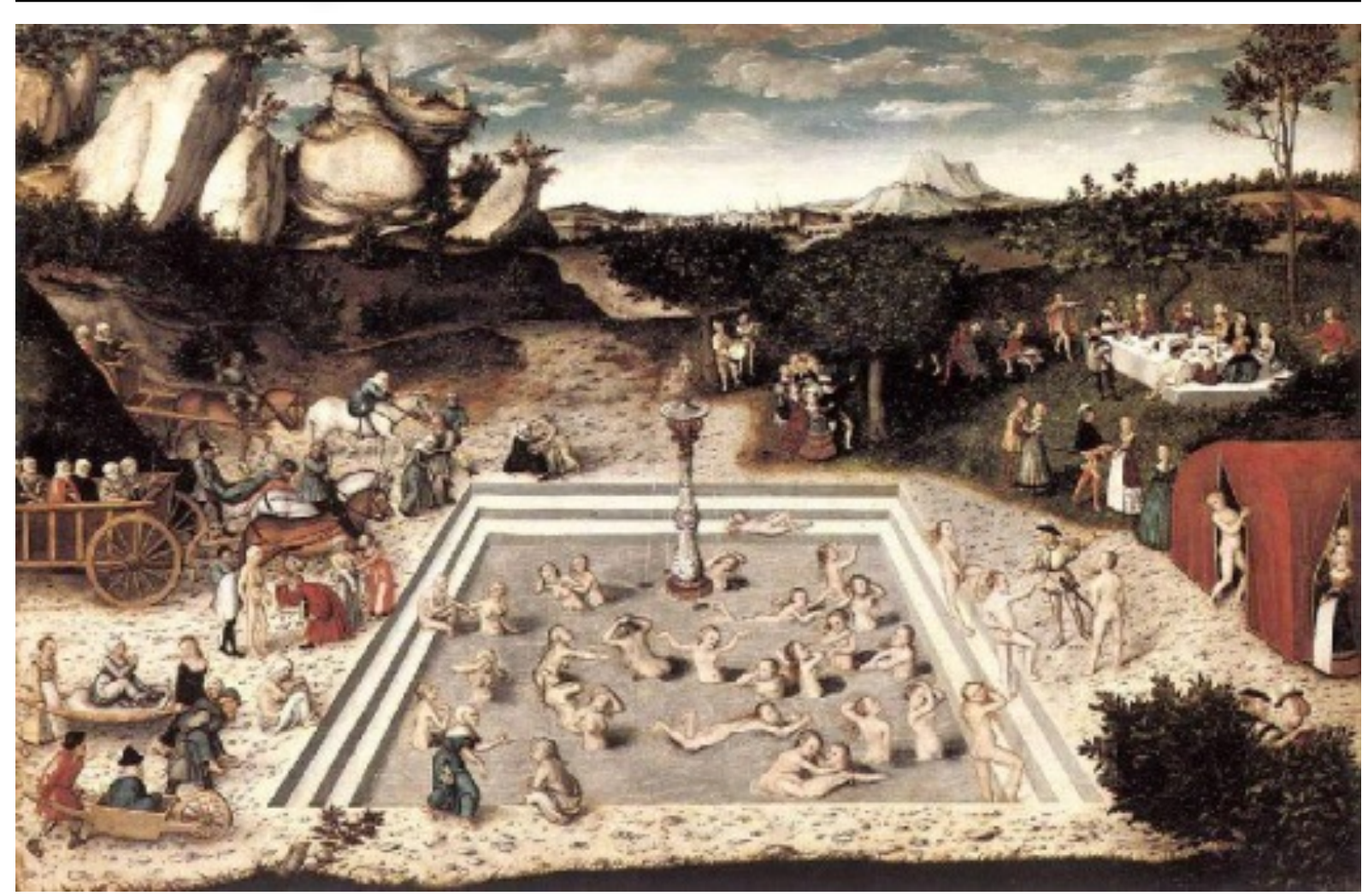

Figura 1. A Fonte da Juventude. Fonte: Wahooart. Disponível em:

<http://pt.wahooart.com/@@/8CABTF-Lucas-Cranach-The-Elder-o-fonte-de-juventude>. Acesso em 02 de mai de 2018.

Segundo Fortes, [...]

[...] este quadro retrata o ambiente de uma paisagem onde se encontra um lago ou fonte para onde são trazidas velhas mulheres que surgem pelo lado esquerdo da cena e, ao adentrar o lago, dirigem-se para o lado direito e vão sendo remoçadas até saírem do lago como jovens e serem abraçadas por homens galanteadores. É interessante notar que apenas as mulheres entram na fonte em busca da juventude; aos homens a aparência e a preocupação com a idade não seriam tão importantes (Fortes, [s.d], p.2).

Ainda segundo o mesmo autor ([s.d], p.4), há várias personagens femininas relacionadas à água, como ele próprio exemplifica: sereias, ondinas, melusinas, Iemanjá e Janaína são algumas. De acordo com ele, várias personagens femininas são retratadas pela história da arte, como Ophelia do texto "Hamlet", de Shakespeare:

Ophelia era uma bela jovem apaixonada por Hamlet. Devido a suas dúvidas existenciais e à preocupação sobre quem teria matado seu pai, Hamlet dá pouca atenção a Ophelia, que enlouquece de amor. Um certo dia, Ophelia, que vagava pelo reino declamando poemas de amor, sobe em um salgueiro à beira do rio, cujo galho se quebra levando-a a cair na água e se afogar. Sem perceber, Ophelia ainda flutua enquanto recita versos apaixonados, até ser totalmente tragada pelo rio (Fortes, 2006, p.27).

Desta forma, o autor explica que "Ophelia é interpretada como uma personagem que busca a morte, e que "nasceu para morrer nas águas" (Fortes, 2006, p. 27). Segundo ele, "a sedução das águas e a vontade de dissolver-se totalmente no líquido é o que a atrai" (2006, p. 27), e complementa dizendo que a morte da personagem trata-se de "uma morte bela e idealizada, de um sofrimento lento de uma alma apaixonada e enlouquecida, e não apenas de um debater-se corporal" (2006, p. 27).

Também na Bíblia é possível encontrar simbologias da água e relacioná-la com a mulher. Assim como a mulher é sinônimo de vida, a água também traduz esse significado. São muitas as relações entre a mulher e a água. Na Bíblia, por exemplo, o episódio do primeiro milagre de Jesus, quando sua mãe, Maria, expõe o problema da falta de vinho no casamento que acompanhavam, e 
então, Jesus, transforma a água em vinho; na passagem entre Jesus e a Samaritana, em que Ele oferece a ela a 'Água viva', fazendo referência a si próprio. "A boa nova anunciada por Cristo, através da metáfora da "água viva", rompe as barreiras como somente as águas têm capacidade para fazer. Rios de água viva proporcionam vida, saúde e abundância, porque são permanentes" (Pinto, 2014, p. 41). Desta forma, Fortes ([s.d], p. 1) aborda que:

O simbolismo da água como fonte de vida é mencionado em quase todas as cosmogonias, desde o Gênesis, na Bíblia, até o Alcorão, ou mesmo em escritos pagãos, como os do filósofo grego Aristóteles, que cita Thales de Mileto (624-546 a.C) ao afirmar que a água seria o elemento original ou o princípio de todas as coisas. As representações da relação entre água e religião e sua simbologia como elemento primordial podem ser encontradas desde as pinturas pré-renascentistas em que começam a surgir as pequenas paisagens de fundo nas quais podem-se ver pequenos rios serpenteantes (Fortes, [s.d], p. 1).

Na produção de arte contemporânea, Fortes escreve que é possível encontrar exemplos em que as relações entre água e corpo são fundamentais. "As conexões entre água, sexualidade, vida e morte parecem ser uma constante nestes trabalhos". (Fortes, [s.d], p. 5). Sendo assim, o autor explana:

Ora a água é utilizada como material para performances, ora ela compõe instalações interativas que estimulam os sentidos, ora surge misturada a pigmentos vermelhos em uma forte referência ao sangue. A maior parte destes trabalhos aparece a partir da década de 60, quando a tentativa de aproximação da arte e da vida começa a se impor na história da arte e o trabalho artístico passa a assumir formas diversas daquelas oferecidas pelos meios e gêneros artísticos tradicionais (Fortes, [s.d], p. 5).

Chaia (2016, p. 74) exemplifica a utilização da água na arte de Sandra Cinto. De acordo com o autor, Sandra Cinto desde 1992 inicia as pinturas da série "Nuvens", até 2016, e utiliza-se da metáfora da água para "produzir sua arte e para produzir conhecimento sobre os significados da existência".

Por exemplo, na recente exposição na Casa Triangulo (abril de 2016), em São Paulo, não apenas as duas grandes telas e os desenhos contrapõem a água de verdade com as rochas desenhadas minuciosamente, mas também a potente escultura-instalação, ao reproduzir uma ponte, supõe a água passando por baixo como uma necessidade de união de margens separadas por obstáculos naturais: a água como presença ausente (Chaia, 2016, p.74).

Para tanto, além das relações entre mulher e água - outro complemento é encontrar a água presente na arte, por meio do relacionamento entre a pintora e água como ferramenta de trabalho e protagonista da própria arte.

Deste modo, relacionar mulher e água é organizar essa dinâmica do ponto de vista histórico, artístico, cultural e até no âmbito da beleza.

A relação entre água e feminilidade é frequentemente destacada por vários autores. $A$ fertilidade, a sensualidade, a flexibilidade e a instabilidade são atributos geralmente relacionados à mulher e também presentes no elemento aquático (Fortes, 2006, p. 27).

Assim, a reflexão dessa relação - mulher e água — não fica limitada e sujeita somente ao significado feminino apegados aos interesses do lar e filhos. 0 do termo "mulher" pode ser atualizado para outros contextos que dizem respeito à água. "A umidade do sexo feminino necessária nos processos de sedução também pode ser associada à água" (Fortes, 2006, p. 27).

É preciso estabelecer uma nova definição de "mulher", atualizando-a e expondo seus papeis na história com relação à água, de forma a torná-las, mulher e água, sujeitos e objetos, atribuindo a essa organização significados complementares aos tradicionais, de certa forma, modificando-os, mas também os completando:

Ao refletir sobre as diversas possibilidades de pesquisa a relação entre gênero e água seria possível fazê-la a partir de contextos diversos, realidades caracterizadas pela água 
abundante ou também por conflitos desenhados em torno da qualidade da mesma, isso para indicar apenas alguns caminhos. Cada uma dessas possibilidades constitui-se em múltiplos objetos e cada um deles demanda um olhar específico (Soares, 2009, p. 33).

É interessante refletir que a relação mulher e água é antiga e permanente, pois continua presente no cenário atual. Porém, é preciso enxergar essa correlação de maneira diferente aos ideais tidos como "machistas". Percebe-se que apesar das conquistas alcançadas pelo público feminino, como diz Soares $(2009$, p. 41) “...em meados do século XX, maior parte dos países ocidentais tem voto, estudo e trabalho reconhecidos como direitos das mulheres". Já é o momento de adequar melhor o vocábulo "mulher" como sinônimo de representação para a "vida", mas ir, além disso, uma vez que a Constituição da República Federativa do Brasil (Brasil, 1988), em seu Art. 5o diz: "Todos são iguais perante a lei, sem distinção de qualquer natureza, garantindo-se aos brasileiros e aos estrangeiros residentes no País a inviolabilidade do direito à vida, à liberdade, à igualdade, à segurança e à propriedade..."

Desta forma, não é possível ignorar o fato de que o público feminino continuará a gerar vida; entretanto, o público feminino, conforme expresso no Art. 5o já mencionado, também possui os direitos citados, além de muitos outros, no entanto, é interessante apontar para o direito à igualdade e à vida, porém, o direito a uma vida digna. Nesse sentido, é essencial que haja uma redefinição sobre os valores da mulher, que deve ser contrária a ideias machistas e também aos modelos tradicionais, de forma que a mulher deixe de ser referenciada como objeto doméstico, de desejo e obrigações. A mulher, assim como a água, deve ser "preservada", não apenas como mãe e esposa, mas também como profissional, como sujeito de direitos, deve ser "apreciada", "bem tratada", ou seja, bem cuidada e respeitada no ambiente familiar e fora dele, em espaços profissionais, públicos e privados.

Apesar das mudanças na lei e nos pensamentos da sociedade, em muitos lares e em diversas culturas no Brasil e no mundo a mulher ainda é criada ou educada com a função de "servir", por exemplo, água, o que ainda permite conferir a ela a relação com a água em vários momentos:

A mulher agricultora do semi-árido mantém estreita relação com o recurso natural água, sendo praticamente a responsável pela água para o consumo da família para fins de beber, preparo dos alimentos e higiene pessoal. Além disso, ela desempenha várias atividades que necessitam diretamente do uso da água, como o cultivo agrícola e o cuidado dos animais de pequeno porte. Apesar disso, ela não é pensada como sujeito ativo dos programas relacionados à água da região semi-árida do Brasil (Melo, 2006, p. 174-175).

Soares (2009)completa esse raciocínio ao escrever que a situação é agravada "quando o acesso à fonte de água mais próxima encontra-se a quilômetros demandando horas diárias de caminhada":

Essas longas jornadas de 'trabalho doméstico' têm forte impacto sobre a economia do lar e a economia nacional, tendo em vista seus desdobramentos na educação, ao dificultar o acesso das crianças e jovens à escola; na saúde, ao aumentar a demanda por atendimento hospitalar e, consequentemente, na carga tributária e na vida associativa da sociedade, pois o tempo gasto nesses trabalhos dificulta a participação das mulheres nas outras atividades das organizações locais (Soares, 2009, p. 34).

A mulher, historicamente, tem a função de captar esse recurso natural para a família. Em um cenário de escassez hídrica, os poços ou açudes de água encontram-se distante do local de residência. Dessa forma, as mulheres e meninas perdem muitas horas em busca da água, quando poderiam utilizar esse tempo para estudar e trabalhar (Fiocruz Minas, 2016).

Em 2016, durante a Semana Mundial da Água, em Estocolmo, na Suécia, o Fundo das Nações Unidas para a Infância (UNICEF) declarou que mulheres e meninas do mundo gastaram 200 milhões de horas por dia coletando água (ONU, 2016). Ainda segundo a UNICEF: "na África Subsaariana, uma caminhada para coletar água dura em média 33 minutos nas áreas rurais e 25 minutos nas áreas urbanas (ONU, 2016)".

Segundo Neves-Silva e Heller (2015): 
Em Gana, foi observado que ao reduzir o tempo de coleta de água em 15 minutos, aumentava-se de 8 a 12\% o número de meninas entre 5 a 15 anos que frequentavam a escola; já no Iêmen e Paquistão, ao reduzir o tempo de coleta em uma hora, aumentava-se a frequência das meninas na escola em 10 e 12\% respectivamente (Neves-Silva \& Heller, 2015, p. 1866).

A dificuldade do acesso à água acarreta outros problemas, além do tempo gasto na busca desse recurso natural. Neves-Silva e Heller (2015) afirmam que, muitas das vezes, as mulheres e as crianças se tornam vulneráveis à violência e aos abusos sexuais, durante o percurso da coleta de água.

A seção seguinte retrata um exemplo da realidade brasileira, no qual as mulheres do semiárido nordestino encontraram nas cisternas um possível caminho para facilitar o acesso à água.

\section{A mulher sertaneja, a água e as cisternas.}

Quando nos referimos à mulher sertaneja, do semiárido nordestino, essa realidade é ainda mais distante. A mulher no semiárido nordestino preserva uma relação íntima com a natureza, mais especificamente, com a água (Melo, 2012). A mulher no semiárido nordestino tem um papel central dentro da família: ser a responsável por buscar água. Segundo Melo (2012):

O manejo, a conservação e a gestão, representam práticas adotadas pela mulher agricultora que cotidianamente utiliza a água para realizar atividades produtivas, bem como para o abastecimento da unidade familiar: o consumo doméstico (Melo, 2012, p.1).

Sob o atual cenário, de escassez hídrica, devido ao aquecimento global, o trabalho da mulher sertaneja - em abastecer o lar com a água - encontra-se comprometido. A mulher, no semiárido, trabalha em condições hostis, onde, muitas das vezes, o local de abastecimento da água encontra-se muito distante do domicílio, isso sem mencionar o clima inóspito (Melo, 2010).

Sob esse contexto, é essencial que as mulheres sejam envolvidas de forma ativa na elaboração de programas governamentais e não governamentais relacionados à água, como, por exemplo, na implementação das cisternas'1. Sonda et al (2001) dialoga com Pontes (2013), ao afirmarem que houve de fato uma melhoria na qualidade de vida das mulheres. Segundo um estudo realizado por Sonda et al (2001, p. 04), as mulheres "acordavam de madrugada, entre 24:00 h a 4:00 h e

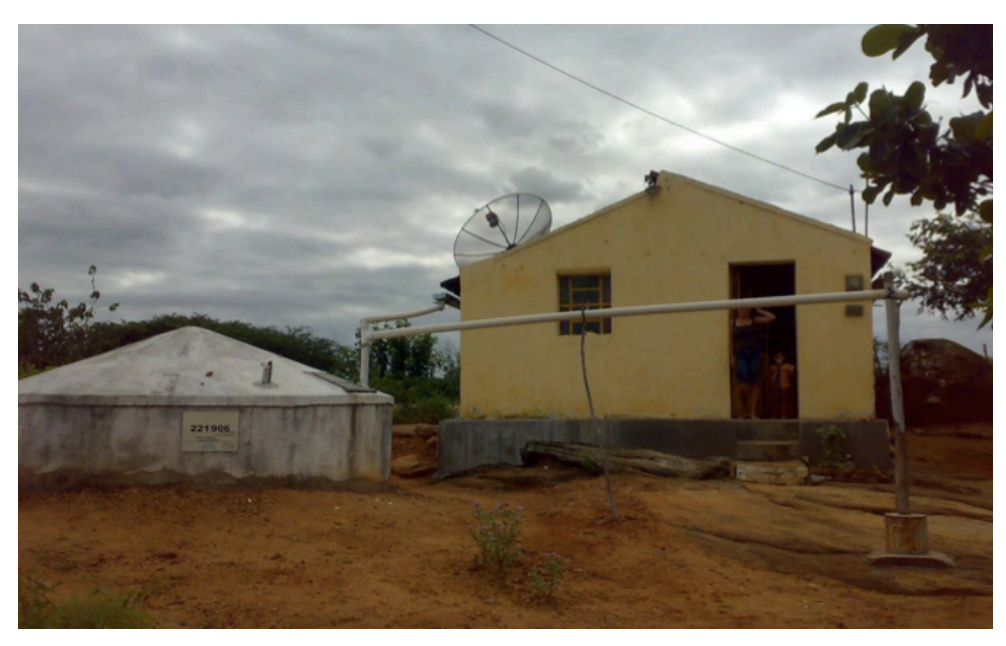
andavam cerca de 1 a $6 \mathrm{~km}$ até as fontes mais próximas, normalmente, cacimbas ou açudes". As cisternas revolucionaram a relação entre a mulher e a água, marcando o fim das longas caminhadas, com peso dos potes de água na cabeça. A Figura 2 ilustra uma cisterna no nordeste brasileiro.

No entanto, as mulheres ainda tem um papel passivo no que se refere a sua participação para implementação de projetos desse gênero. Apesar de serem elas, as grandes afetadas pela ausência de programas que buscam resolver o estado crítico dos ambientes afetados por secas, são os homens quem tomam as decisões práticas, além de selecionar os locais e as comunidades que

\footnotetext{
${ }^{1}$ Segundo Sonda (2001, p. 04): “cisterna é um reservatório de águas chuvas, de uso antigo e, conhecido do Semi-Árido brasileiro, desde o século XIX, época das secas históricas. Porém, foi a partir das três últimas décadas que a prática da cisterna foi disseminada na Região".
} 
serão beneficiadas (Melo, 2010). Para Pontes (2013, p. 19): “O papel das mulheres no semiárido é um retrato de como são fortes e poderosas, mesmo nem todas tendo consciência disso".

Mas não somente a mulher do semiárido mantém estrita relação com a água, como também a mulher que reside na área urbana, a mulher criança, a mulher adolescente e a mulher jovem e adulta, afinal, em todo lar é necessário lavar louça, lavar roupa, fazer a limpeza da casa, regar as plantas e preparar alimentos. Essas tarefas, na maioria dos lares, ainda continua sendo uma incumbência feminina. "Na falta de água, o duro trabalho de abastecer os lares aparece nas mais diferentes culturas como uma tarefa das mulheres de todas as idades, inclusive das crianças" (Soares, 2009 , p. 34). Entretanto, o papel da mulher com relação à água não deve ser apenas no contato manual e na utilização desse recurso, como também na gestão dele, o que envolve, conjuntamente, teoria e práticas para a melhor utilização e preservação desse recurso, como também na tomada de decisões e na luta de seus direitos em incorporar comitês de bacias e demais grupos e fóruns.

\section{A mulher na tomada de decisão sobre a água}

Ainda no mundo contemporâneo, as mulheres são vítimas de vários constrangimentos com relação à questão de gênero e passam por diversos tipos de transtornos, como, por exemplo, são elas as responsáveis por buscar água, e para isso, precisam percorrer longas distâncias, comprometendo a própria educação, pois deixam os estudos para segundo plano.

Melo (2010, p. 1) diz que tanto as políticas de desenvolvimento criadas para a Região Semi-Árida Nordestina do Brasil, como as demais políticas brasileiras não contemplam a mulher agricultora, e quando a incluem, o fazem de forma parcial. "Outras vezes, a inclusão não passa do papel” (Melo, 2003).

Tal forma de injustiça contra essas mulheres ocorre, mesmo quando mais da metade da população da Região é feminina, e participantes ativas dos trabalhos gerados pela agropecuária, principal setor econômico. Neste sentido, os vários programas, até então criados, para desenvolver o Semi-Árido, a exemplo daqueles relacionados aos recursos naturais afetados pelo fenômeno climático denominado de seca, não incorporam devidamente a mulheres agricultoras, tornando-os assim, praticamente exclusivos, dos homens agricultores (Melo, 2010, p. 1).

Melo (2010) explica que dentre os programas incluem os de curto e os de longo prazo. Os de curto prazo são os programas de efeito imediato e aqueles de caráter emergencial, os velhos conhecidos da população do semiárido e já extintos, como os Programas Federais de Combate aos Efeitos da Seca, também conhecidos por Programas de Emergência. Por outro lado, os programas de longo prazo, segundo a autora, foram criados mais recentemente e pensados a partir da nova perspectiva de sustentabilidade da Região. "Esses programas, a exemplo do Programa de Convivência com a Seca, são da responsabilidade de instituições, tanto governamentais, como não governamentais" (Melo, 2010, p. 2).

Muitas mulheres também lidam com a violência doméstica e com a ignorância de muitas pessoas, especialmente homens, que são contrários à sua formação acadêmica ou que não aprovam sua inserção no mercado de trabalho, ou ainda, não toleram sua opinião e participação na gestão de recursos hídricos.

Apesar das atribuições socialmente impostas a mulher, no que se refere às atividades relacionadas ao abastecimento de água para unidade domiciliar, ela não participa ou tem baixa participação nas decisões e na operacionalização dos programas governamentais $e$ não governamentais formulados para atender a população do Semi-Árido, no que concerne a questão da água para o consumo das famílias. Quem é convocado é o homem, isso porque ele foi o eleito, pelas leis sociais, para representar a família. Desse modo, naturalmente, ele é o convocado para participar, por exemplo, das decisões práticas, ou do funcionamento dos programas, assim como para selecionar as localidades/comunidades beneficiadas. Isso ocorre, mesmo quando, a mulher é a responsável direta pelo abastecimento da água para o consumo familiar. Nesse sentido, é fato a ausência das mulheres agricultoras da Região, nos programas de obras para o aproveitamento das águas pluviais, através de cisternas (Melo, 2010, p.4). 
Desta forma, Melo (2010, p. 5) também chama a atenção ao dizer que as mulheres não participam das decisões que envolvem o programa de cisternas, pois é o homem quem escolhe a propriedade a ser beneficiada pela obra, bem como o local da construção. "Geralmente, tais decisões acontecem no âmbito das associações rurais ou do outras organizações sociais, instâncias formadas, na maioria, pelo masculino". Além disso, como a autora expõe, fica como responsabilidade do homem a execução da cisterna e os serviços de alvenaria são realizados por pedreiro.

Fischer ([s.d], p. 3) explica que os comitês das bacias hidrográficas são compostos pelo setor público, usuário e sociedade civil, e que a maioria das políticas públicas possui "ranços patriarcais que dificultam a participação das mulheres em vista do seu sexo". A autora exemplifica que no Comitê do rio São Francisco todos os representantes de consórcio e associação de usuário pertencem ao sexo masculino e há vários consórcios e associações de gerenciamento de água, "porém, poucas mulheres assumem representação nesses consórcios" (Fischer, [s.d], p. 4). De acordo com a autora tal fato é explicado, principalmente, porque a "participação da mulher no comitê de bacia ameaça a dinâmica de funcionamento da rotina cotidiana da família e introduz uma nova visão no gerenciamento da água" (Fischer, [s.d], p.5) e "cria dificuldades à prática da dupla jornada de trabalho, possibilitando a liberação da mulher dessa carga patriarcal que carrega durante séculos" (Fischer, [s.d], p. 8).

De acordo com a matéria publicada pelas repórteres Franzin; Sinimbú; Ferreira (2018) são poucas as mulheres nos cargos de gestão dos recursos hídricos. Sendo assim, em entrevista para a reportagem, a Professora adjunta da Universidade do Estado do Rio de Janeiro (UERJ) e ex-diretora de Gestão das Águas e do Território do Instituto Estadual do Ambiente, Rosa Formiga, diz que a relação com o gênero é muito forte, uma vez que o acesso à água vai liberar a mulher para estudar e ter outros afazeres, como se tornar uma profissional, o que é frequente, segundo comenta, na África, na Ásia e no semiárido brasileiro.

Por outro lado, Fischer chama a atenção ao dizer que "membros de comitês têm o entendimento de que a mulher é fraca por não afrontar posicionamentos masculinos, da mesma forma que fazem os homens" (Fischer, [s.d],p. 4). Porém, defende a classe feminina ao apontar que esta tem maneiras diferentes de agir, o que não é sinônimo de fraqueza:

Elas têm estratégias próprias de incomodar o poder sem afrontá-lo, fazendo isto através da crítica verbal dosada por certo respeito, mas, certamente, ameaçadora. 0 fato de elas costumarem, por exemplo, ter uma comunicação mais abrangente do que o seu companheiro masculino junto à comunidade, à família e a própria sociedade, o que lhe confere a condição de matriz cultural, pode facilmente causar desgaste e descrédito a pessoas, a programas e a políticas públicas. Independentemente do seu posicionamento no comitê, ela pode juntamente com a sua comunidade exercer o controle social e impedir que políticas direcionadas a água sejam efetivadas (Fischer, [s.d], p. 4).

Ela ainda complementa o seu raciocínio ao tratar que "o objetivo das mulheres que representam a sociedade civil é a defesa da água para o uso comum em suas comunidades e a conservação dos mananciais", e afirma que devido à representação das comunidades surgem embates pelo uso da água no contraponto entre os interesses político, econômico e social (Fischer, [s.d],p. 4).

Essas argumentações permitem entender que na questão mulher e água o público feminino não é reconhecido como deveria, e acaba não possuindo o direito de tomar decisões ou participar de conselhos, fóruns e decisões políticas, ou isso acaba ocorrendo de maneira mais seletiva. É possível trazer tais conceitos para a atualidade, de modo a não permanecer em significados restritos à falta de condição de a mulher também ser objeto da história, afinal, a correlação mulher e água é mais profunda do que se pode imaginar a primeiro momento, e os hábitos, costumes e tarefas do público feminino sempre estiveram presentes no cotidiano da mulher, ainda que despercebidos, através da história, tornando ambas - mulher e água - objetos e sujeitos da história, mesmo que ainda não sejam reconhecidas desta maneira, como por exemplo, ao tratar da participação e tomada de decisões em Comitês de Bacias Hidrográficas, Agências de Bacias, Conselhos estaduais, câmaras técnicas e conselho nacional: 
Tendo em vista que o arcabouço institucional que ampara a Política Nacional de Recursos Hídricos (PNRH) preconiza que o gerenciamento desses recursos deve ser descentralizado e participativo, discutir a incorporação da perspectiva de gênero no Sistema Nacional de Recursos Hídricos (SINGREH) passaria naturalmente por discutir a participação de mulheres nas várias instâncias (comitês de bacias hidrográficas, agencias de bacias, conselhos estaduais, câmaras técnicas e Conselho Nacional) de um sistema tradicionalmente marcado pela presença de homens e pela ausência das mulheres (Soares, 2009, p.32).

Este cenário precisa ser modificado. Infelizmente, não há apenas pontos positivos nas relações que podem ser feitas entre água e mulher e vice-versa:

Grosso modo, é possível afirmar que os simbolismos da água ocupam, na verdade, pólos opostos no imaginário humano. Ao mesmo tempo em que a água é fonte de vida nas imagens do batismo, ela é a causadora da destruição na iconografia do dilúvio. Se por um lado ela purifica a alma nos rituais místicos, por outro ela incita à sensualidade e ao desejo ao molhar o corpo. Embora nem todas as obras que utilizem a água como tema ou material tratem da relação entre água e corpo, pode-se dizer que esta é uma das associações mais frequentes e ricas em significação (Fortes, [s.d], p. 5).

Algumas alterações interessantes em algumas áreas já foram estabelecidas, como na Conferência das Nações Unidas sobre Meio Ambiente e Desenvolvimento no Rio de Janeiro em Junho de 1992, quando, de acordo com a Universidade do Estado do Rio de Janeiro (UERJ):

Ao recomendar a Declaração de Dublin a todos líderes mundiais reunidos na Conferência das Nações Unidas sobre Meio Ambiente e Desenvolvimento no Rio de Janeiro em Junho de 1992, os participantes da Conferência incentivaram todos os governantes a estudarem cuidadosamente as atividades específicas e os meios de implementação recomendados no Relatório da Conferência, e traduzir aquelas recomendações em urgentes programas de ação para Água e Desenvolvimento Sustentável (2007, p. 1).

Sendo assim, o Relatório da Conferência sugere várias recomendações de ação a nível local, nacional e internacional, baseado em quatro princípios. Entre os princípios, para o enfoque desse trabalho é interessante apontar a relevância do Princípio №3 - As mulheres formam papel principal na provisão, gerenciamento e proteção da água:

Princípio $N^{\circ} 3$ - As mulheres formam papel principal na provisão, gerenciamento e proteção da água: Este papel de pivô que as mulheres desempenham, como provedoras e usuárias da água e guardiãs do ambiente diário não têm sido refletidos na estrutura institucional para o desenvolvimento e gerenciamento dos recursos hídricos. A aceitação e implementação deste princípio exige políticas positivas para atender as necessidades específicas das mulheres e equipar e capacitar mulheres para participar em todos os níveis dos programas de recursos hídricos, incluindo tomada de decisões e implementação, de modo definido por elas próprias (2007, p. 1).

A afirmação acima precisa ser colocada em prática em sua totalidade. Trata-se de um processo longo. 0 acesso universal e igualitário à água, por exemplo, uma das metas (sexta meta) dos Objetivos do Desenvolvimento Sustentável (ODS)², ainda está longe de ser alcançado. Para tanto, é essencial que os formuladores de políticas públicas envolvam as mulheres, e levem em consideração o contexto social em que estas estão inseridas, para que as metas da ODS sejam alcanças.

Franzin; Sinimbú; Ferreira (2018) discorrem que apenas em 1992, na Conferência de Dublin, da qual participaram representantes de 80 organismos internacionais, intragovernamentais e não governamentais, com o objetivo de discutir Água e Meio Ambiente, foi reconhecido o papel central e estratégico das mulheres na provisão, na manutenção e na gestão da água, mas que ainda há questionamentos sobre a incorporação do princípio na Política Nacional de Recursos Hídricos, de 1997, então é preciso que a mulher participe no Sistema Nacional de Recursos Hídricos e comitês de bacia.

2 Os ODS são exemplo de uma parceria global com a participação ativa de todas as partes interessadas, incluindo governos, sociedade civil, academia, setor privado, mídia e as Nações Unidas. 
No entanto, Cardoso (2003, pp. 25-27) critica que "é interessante notar que o principio número 3 da declaração de Dublin, sobre o protagonismo da mulher na gestão e proteção da água, não foi tomado em conta na legislação e política brasileiras". Para Soares $(2006$, p. 67) apesar do novo modelo de gestão de recursos hídricos ter sido desenhado em torno de princípios a partir da agenda internacional, "é curioso observar que todas as recomendações propostas foram, de uma forma ou de outra, incorporadas na nova política, com exceção do princípio que trata da incorporação da perspectiva de gênero.

Cardoso (2003, p. 27) lamenta ao longo de sua pesquisa não ter encontrado quase nenhuma referência sobre o protagonismo da mulher na gestão e proteção da água não ter sido tomado em conta na legislação e política brasileiras, e que a única referência encontrada foi através da internet, a Gender and Water Alliance (GWA), que segundo a autora pontua, trata-se de uma rede internacional que busca a incorporação da perspectiva de gênero na gestão de recursos hídricos, através da promoção do debate da questão e divulgação de experiências. A autora complementa seu raciocínio ao escrever que em 2001, no IV Diálogo Interamericano de Gerenciamento de Águas, ocorreu a iniciativa de discutir o tema no país, proposta esta feita por integrantes da Rede citada, porém, que o tema não ocupou uma posição política de destaque. "Pode-se em parte explicar essa ausência pelo fato da lei ter sido elaborada por pessoas (homens e mulheres, vale ressaltar, embora os primeiros sejam maioria) provenientes das áreas técnicas, em que as interações com movimentos sociais se davam mais na área ambiental". Sendo assim, Cardoso (2003, p. 27) diz que o movimento feminista brasileiro não possui uma história de atuação nas políticas ambientais, "embora referências a uma perspectiva de gênero e meio ambiente sejam mais frequentes na bibliografia, do que aquelas relativas a gênero e recursos hídricos especificamente", e argumenta que são pontuais as referências a uma incorporação da perspectiva de gênero na gestão de águas ou de um protagonismo da mulher, relativas a casos concretos ou ao manejo de água nas áreas rurais do semiárido.

Há ainda a visão muito comum que trata a relação 'mulher-água' de uma perspectiva essencialista, romantizada, seguindo os cânones do ecofeminismo que identifica a mulher como mais próxima à natureza e, portanto, portadora de um conhecimento intrínseco sobre o meio ambiente e sua guardiã 'natural' (Cardoso, 2003, p.27).

Sobre tal assunto abordado na citação acima, Melo (2010, p. 1) realmente defende o que Cardoso (2003) critica: que "no território rural a mulher trabalhadora da agricultura mantém íntima relação com a natureza". No entanto, Melo explica que:

No rol dos recursos naturais, a água é um dos principais recursos por ela utilizado. $O$ manejo, a conservação e a gestão, representam práticas adotadas pela mulher agricultora que cotidianamente utiliza a água para realizar atividades produtivas, bem como para o abastecimento da unidade familiar: o consumo doméstico (Melo, 2010, p. 1).

Entretanto, mesmo que Melo (2010) diga que a mulher mantém íntima relação com a água, também expõe que:

As mulheres agricultoras da região, embora mantendo relação próxima e ampla com a água, em decorrência das diversas atividades que realizam, e sejam mais diretamente afetadas pelos danos causados á água, sempre estão à margem das decisões políticas, bem como dos processos tecnológicos relacionados à água, na Região. (Melo, 2010, p. 1).

Por fim, Cardoso (2003, p. 27) conclui que "não se encontra uma discussão sobre gênero e água no âmbito de políticas, da mesma forma como é muito raro a participação de organizações de mulheres nos Comitês de Bacias Hidrográficas". Para ela, ao longo de 2002 a rede internacional Gender Water Alliance promoveu uma conferência eletrônica sobre 'Gênero e Água' entre países de língua portuguesa, que contou com uma maior participação de brasileiros.

Nota-se nos debates essas duas tendências apontadas anteriormente: focalizar a discussão no nível local e em ações concretas, e um tratamento do tema do ponto de vista do ecofeminismo. Algumas poucas questões foram levantadas relativas a uma política pública com perspectiva de gênero, e à participação de mulheres ou organizações de mulheres nos Co- 
mitês de Bacias. Por outro lado, as pessoas que participaram da lista e que contribuíram de forma mais efetiva geralmente estão ligadas a organizações de âmbito local, não exercendo um papel protagonista dentro do campo de recursos hídricos. Isso reforça a forma ainda marginal mostrando como o tema é tratado dentro desse campo (Cardoso, 2003, p. 27).

Tal cenário com relação à mulher na gestão da água vem se alterando, e várias matérias atuais contribuem para mostrar essas modificações, pois a conscientização está tomando conta do público feminino ao que se refere à participação maior da mulher na tomada de decisões sobre esse recurso, afinal, uma relação que é íntima, que é diária, e aborda questões sociais, artísticas e culturais também deve ser levada para o âmbito da política, o que é de suma importância, pois a esta última área estão atreladas também questões que envolvem o nível ambiental. Nesta questão, Franzin, Sinimbú, e Ferreira (2018) dizem que enquanto as mulheres são minoria nos altos cargos de decisão, elas estão entre as mais atuantes na defesa e no uso sustentável da água. As autoras apontam que "um dos grandes desafios para aumentar a participação feminina na gestão de recursos hídricos é a ausência de dados sobre a relação água e gênero".

Também em sua matéria abordam sobre a Agência Nacional de Água - ANA — estar trabalhando no Projeto Legado, criado em dezembro de 2017, com o objetivo de levantar propostas de melhorias na gestão de recursos hídricos, dando ênfase ao papel da mulher, além de alterar a Lei 9.433/1997 (Brasil, 1997), que instituiu a Política Nacional de Recursos Hídricos, para adicionar os princípios de Dublin. Desta forma, para isso, escrevem que o Projeto Legado seria a pauta do 8o Fórum Mundial da Água, já ocorrido entre os dias 18 e 23 de março, em Brasília. "No fim de 2017, a ANA realizou uma oficina internacional de gênero e água, com a presença de mais de 60 mulheres de diversos países que discutiram o assunto. 0 tema retornará ao Fórum" (Franzin, Sinimbú, \& Ferreira, 2018).

Para incentivar a participação delas, a pesquisadora da UnB Daniela Nogueira defende capacitações específicas - para homens e mulheres. "Estamos pensando na criação de uma rede latino-americana de água e gênero justamente para formular estratégias concretas de como nós poderemos impactar na implementação de políticas públicas sobre o tema", afirma (Franzin, Sinimbú, \& Ferreira, 2018).

A metodologia empregada no presente trabalho é a pesquisa bibliográfica, que de acordo com Stumpf (2010, p. 51) trata-se de um conjunto de procedimentos que possui o objetivo de identificar informações bibliográficas, bem como selecionar os documentos pertinentes ao tema estudado e proceder à anotação ou fichamento das referências e dos dados dos documentos, para posteriormente serem utilizados na redação de um trabalho acadêmico. Ainda segundo a autora:

Pesquisa bibliográfica, num sentido amplo, é o planejamento global inicial de qualquer trabalho de pesquisa que vai desde a identificação, localização e obtenção da bibliografia pertinente sobre o assunto, até a apresentação de um texto sistematizado, onde é apresentada toda a literatura que o aluno examinou, de forma a evidenciar o entendimento do pensamento dos autores, acrescido de suas próprias idéias e opiniões (Stumpf, 2010, p.51).

\section{Considerações finais}

Sob o preâmbulo desenvolvido, fica claro a existência de uma relação entre mulher e água. Do ponto de vista histórico, artístico, social e cultural, ambas - mulher e água - sempre tiveram uma íntima relação. A representação desse casamento pode ser observada em diversas obras e em diversos momentos da história. No entanto, o que se vê ao longo dos anos é uma mudança e um estreitamento dessa relação. No sentido de que, a relação mulher-água não se limita apenas aos afazeres domésticos. A água é o componente básico para a manutenção da vida e a mulher é geradora de vida.

É preciso atualizar e redefinir essa relação, de forma que, mulher e água se tornem sujeito e objeto complementares. É necessário envolver a mulher na gestão e proteção da água, uma vez que a escassez deste recurso a afeta com mais intensidade do que aos homens. Isso ocorre também por continuarem sendo elas as responsáveis em muitas comunidades de diferentes regiões do mundo a buscar água, mesmo expostas à violência ou abusos sexuais durante o percurso, o que as torna social e economicamente dependentes da água. 


\section{Referências}

Azevedo, P. S. A.; Pereira, F. W. L.; Paiva, S. A. R. (n.d.) Água, Hidratação e Saúde. Recuperado de: <https:// dicionariodoaurelio.com/mulher>.

Borsa, J. C.; Feil, C. F. (n.d.) O papel da mulher no contexto familiar: uma breve reflexão. Portal dos psicólogos: 2008. Recuperado de: <

Brasil (1988) Constituição da República Federativa do Brasil. Recuperado de:

<http://www.planalto.gov.br/ccivil_03/constituicao/constituicaocompilado.htm>

Brasil (1997) Política Nacional de Recursos Hídricos - Lei 9433/1997. Recuperado de:

<http://www.planalto.gov.br/ccivil_03/leis/19433.ht>

Cardoso, M. L. M. (2003). A demografia das águas na sua prática: O caso dos comitês de Bacias Hidrográficas de Minas Gerais. Museu Nacional.

Chaia, M. (2016) Arte e água na obra de Sandra Cinto. Revista do Centro de Pesquisa e Formação, São Paulo, n. 3, p.73-82, nov. Recuperado de:

<https://www.sescsp.org.br/files/artigo/f5a3b5ca-e9a5-4075-9a3d-5a3d257c2a45.pdf>

Costa, I.H., \& Androsio, V.O. (n.d.) As transformações do papel da mulher na contemporaneidade. Recuperado de: <http://srvwebbib.univale.br/pergamum/tcc/Astransformacoesdopapeldamulhernacontemporaneidade.pdf>

Universidade do Estado do Rio de Janeiro (2007) Declaração de Dublin. Recuperado de:

<http://www.meioambiente.uerj.br/emrevista/documentos/dublin.htm>

Ferreira, A. B. H. Novo dicionário da língua portuguesa (n.d). Recuperado de: $<$ https://dicionariodoaurelio.com/agua>

Ferreira, V.R.T. (2002) Casais de ontem, casais de hoje. Mudanças no casamento e em duas gerações de casais. In: Cenci, C.M.B, Piva, M., \& Ferreira V.R.T. Relações familiares: uma reflexão contemporânea. Passo Fundo: UPF Editora.

Fiocruz Minas (2016). Acesso à água e ao saneamento reflete desigualdade de gênero. Recuperado de: https://portal.fiocruz.br/noticia/acesso-agua-e-ao-saneamento-reflete-desigualdade-de-genero.

Fischer, I.R. (n.d.). A participação das mulheres na gestão da água no espaço público: rebatimentos nas relações familiares. Gênero, desigualdades e cidadania. Recuperado de: <http://actacientifica.servicioit.cl/ biblioteca/gt/GT11/GT11_RufinoFischerI.pdf>

Fortes Júnior, H. F. S. (2006). Poéticas líquidas: a água na arte contemporânea. São Paulo. Recuperado de: <http://www.teses.usp.br/teses/disponiveis/27/27131/tde-13082009-155421/.../923480.pdf>

Fortes, H. (n.d.) Água: significados e simbologias na arte contemporânea. Recuperado de: <http://www.ip.usp.br/laboratorios/lapa/versaoportugues/2c91a.pdf>

Franzin, A., Sinimbú, F., \& Ferreira, P. (2018). Mulheres lutam por espaço na gestão da água no país. Recuperado de: <http://agenciabrasil.ebc.com.br/geral/noticia/2018-03/mulheres-brigam-porespa\%C3\%A7o-na-gest\%C3\%A3o-da-\%C3\%A1gua-no-pa\%C3\%ADs>.

Guiraldelli, R.(2012). Adeus à divisão sexual do trabalho? desigualdade de gênero na cadeia produtiva da confecção. Soc. estado, Brasília, 27(3), 709-732, Dec. Recuperado de: <http://www.scielo.br/scielo.php? script=sci_arttext\&pid=S0102-69922012000300014\&lng=en\&nrm=iso >.

Leloup, J.Y. (2000) O Evangelho de João. Tradução: Guilherme João de Freitas Teixeira. Petrópolis: Vozes. 
Malacarne, J. (2017). Líquido amniótico: tudo o que você precisa saber sobre ele. Revista crescer. Recuperado de: <https://revistacrescer.globo.com/Gravidez/noticia/2017/06/liquido-amniotico-tudo-oque-voce-precisa-saber-sobre-ele.html>

Melo, L. A. (2010). A mulher agricultora: relação íntima com a água. Fazenda Gênero 9: Diásporas, Diversidades, Deslocamentos. Recuperado de: <http://www.fazendogenero.ufsc.br/9/resources/anais/ 1278442727_ARQUIVO_TEXTOULTIM02010.pdf>

Melo, L. A. (2006). Relações de gênero na convivência com o semi-árido brasileiro: a água para o consumo doméstico. In: Scott, Parry; Cordeiro, Rosineide et al. (Orgs). Agricultura familiar e gênero: práticas, movimentos e políticas públicas. Recife: Ed. Universitária da UFRE. 331.

Melo, L. A. (2003). Relações de Gênero na Agricultura Familiar: o caso do Pronaf em Afogados da Ingazeira. (Tese de Doutorado). Faculdade de Sociologia, Universidade Federal de Pernambuco, Recife, PE, Brasil.

Neves-Silva, P; Heller, L. (2016). 0 direito humano à água e ao esgotamento sanitário como instrumento para promoção da saúde de populações vulneráveis. Ciênc. saúde coletiva, Rio de Janeiro, 21(6) 1861-1870. Recuperado de: <http://www.scielo.br/scielo.php?

script=sci_arttext\&pid=S1413-81232016000601861\&lng=en\&nrm=iso >.

Organização das Nações Unidas (2016). Recuperado de: https://nacoesunidas.org/unicef-mulheres-emeninas-do-mundo-gastam-200-milhoes-de-horas-por-dia-coletando-agua/

Pinto, S. S.P. F. (2014). Água da vida e seus simbolismos na perspectiva do evangelista João: o diálogo de Jesus com a Samaritana. Pontifícia Universidade Católica do Paraná: Jornada interdisciplinar de pesquisa em teologia e humanidades, Recuperado de: <hhttp://www2.pucpr.br/reol/index.php/5jointh?

dd $1=14940 \& d d 2=7418 \& d d 3=p t \_B R \& d d 99=$ pdf $>$

Pontes, E. (2013). A Estreita Relação entre Mulher e Água no Semiárido: o Caso do Programa um Milhão de Cisternas Rurais. Revista Latino-americana de Geografia e Gênero, 4(1), 14-21.

Santos, A.T. (n.d.). A construção do papel social da mulher na Primeira República. Recuperado de: <https:// www.maxwell.vrac.puc-rio.br/14404/14404.PDF>

Soares, D. N. (2009). Gênero e água - desenhos do norte, alternativas do sul: análise da experiência do semiárido brasileiro na construção do desenvolvimento democrático. (Tese de doutorado) Instituto de Ciências Sociais. Universidade de Brasília. Recuperado de: <http://www.repositorio.unb.br/bitstream/ 10482/8055/3/2009_DanielaNogueiraSoares.pdf>

Soihet, R. (1998). História das mulheres e história de gênero: um depoimento. Cadernos Pagu, Rio de Janeiro, 77-87, Recuperado de: <https://periodicos.sbu.unicamp.br/ojs/index.php/cadpagu/article/ view/8634464/2388>

Sonda, C., Batista, K.M., Campos, J.D., Neto, J.R., \& Sampaio, O.B. (2001) A convivência da mulher com o Semi-Árido: a vida antes e depois das cisternas. In: Simpósio Brasileiro de Captação de Água Chuva no SemiÁrido. 1 CD-ROM.

Stumpf, I.R.C. (2010). Pesquisa bibliográfica. In: Duarte, J., \& Barros, A (Orgs). Métodos e técnicas de pesquisa em comunicação. São Paulo: Atlas. 